\section{СПИСОК ЛИТЕРАТУРЫ:}

1. Брюсов А.Я. История древней Карелии // Труды государственного Исторического музея. М.: Издво ГИМ, 1940. Вып. IХ. 320 с.

2. Герман К.Э., Мельников И.В. Археологические исследования в заповеднике «Кивач» в 2014-2015 гг. // Труды Государственного природного заповедника «Кивач». Петрозаводск, 2016. Вып. 7. С. 166-174.

3. Демидов И.Н., Лукашов А.Д., Ильин В.А. Рельеф заповедника «Кивач» и история геологического развития северо-западного Прионежья в четвертичном периоде // Природа Государственного заповедника «Кивач». Труды КНЦ РАН. Вып. 10. Петрозаводск. 2006. С. 22-33.

4. Девятова Э.И. Природная среда и ее изменения в голоцене (побережья севера и центра Онежского озера). Петрозаводск: Изд-во Карельского научного центра РАН, 1986.110 с.

5. Гурина Н.Н. Оленеостровский могильник. М.; Л.: Изд-во «Наука», 1956. 431 с.
6. Журавлев А.П. Пегрема (поселения эпохи энеолита). Петрозаводск: Изд-во Карельского научного центра РАН, 1991. 205 с.

7. Журавлев А.П. Заонежье в эпоху камня - раннего металла. Петрозаводск: Изд-во Карельского научного центра РАН, 1994. 108 с.

8. Мельников И.В., Герман К.Э. Древние поселения южного Заонежья (мезолит - энеолит). Петрозаводск: Изд-во Карельского научного центра РАН, 2013. $406 \mathrm{c}$

9. Мельников И.В., Герман К.Э. Новые открытия древних поселений на озерах Ванчозеро и Космозеро в Заонежье (Медвежьегорский район Карелии) // Кижский вестник. Петрозаводск, 2017. Вып. 17.

10. Сельговые ландшафты Заонежского полуострова. Петрозаводск: Изд-во Карельского научного центра РАН, 2013. $180 \mathrm{c}$.

11. Филимонова Л.В., Лаврова Н.Б. Палеогеография Заонежского полуострова в позднем плейстоцене и голоцене // Труды Карельского научного центра РАН. 2015. № 4. С. 30-47.

\title{
ARCHAEOLOGICAL RESEARCH OF THE EXPEDITION OF THE MUSEUM-RESERVE «KIZHI» IN 2013-2016
}

(C) 2017

German Konstantin Enrikovich, candidate of historical sciences, head of Store Collections Department

Melnikov Igor Valerievich, candidate of historical sciences, deputy director of scientific fund and exposition and exhibition activities

Kizhi State Open-Air Museum of History, Architecture and Ethnography (Petrozavodsk, Russian Federation)

Abstract. The following paper summarizes the study results of the Kizhi Museum-Reserve archaeological expedition in 2013-2016. During this period Kosmozero, Vanchozero, Turastamozero and Ladmozero on the territory of the Zononezhsky peninsula in the Medvezhyegorsk district and the Suna River within the boundaries of the Kivach state reserve in the Kondopoga district were studied. The purpose of the study was to establish the high-altitude patterns in the location of the Stone Age settlements in the interior of the Karelia. As a result of the works 23 ancient settlements on the territory of the Zaonezhsky peninsula were located on the ancient terraces of the Onega Lake bays at heights of 3 to 12 meters above the current water level in the reservoirs, the most ancient monuments of the Mesolithic era occupying the highest hypsometric marks. A new archeological complex of 20 monuments was discovered, timed to the ancient coastal terraces of the Onega Lake and at altitudes of 4 to 14 meters above the modern water level and in the Suna River.

Keywords: Paleogeography; paleoecology; Zaonezhsky peninsula; lake Cosmozero; lake Vanchozero; lake Turastamozero; lake Ladmozero; Suna River; high-altitude patterns; archaeological prospecting; archeological pits; stratigraphy of soil layers; Mesolithic; Neolithic; Eneolithic; ceramics; stone tools.

УДК 902.413(470.55)

Статья поступила в редакцию 05.06.2017

\section{«НАЗАД В БУДУЩЕЕ»: ОСНОВНЫЕ ИСТОРИОГРАФИЧЕСКИЕ СЮЖЕТЫ И АКТУАЛЬНЫЕ ПРОБЛЕМЫ НЕОЛИТА ЗАУРАЛЬЯ}

(C) 2017

\author{
Яковлева Екатерина Сергеевна, научный сотрудник \\ Археологический научный центр (2. Челябинск, Российская Федерация)
}

Аннотация. Статья посвящена некоторым проблемам зауральского неолитоведения, связанным с форми-
рованием и развитием основных культурно-хронологических концепций. В концептуальной историографии
выделены три этапа. Первый относится к середине - второй половине ХХ в. и связан с формированием пер-
вых схем культорогенеза позднего зауральского каменного века В.Н. Чернецовым и О.Н. Бадером, а также
Л.Я. Крижевской. На втором этапе конца ХХ - начала ХХІ в. их идеи были пересмотрены В.Т. Ковалевой в
рамках двухстадийной и двухлинейной концепции. Параллельно разрабатывалась гипотеза В.А. Заха, осно-
ванная на идее сложения зауральского неолита в результате миграции носителей боборыкинской культуры и
постепенной ассимиляции их аборигенами. Несколько позднее В.С. Мосиным была предложена социокуль-
турная схема формирования единого социума в неолите Зауралья. Третий - современный - этап начался
приблизительно во втором десятилетии ХХІ в., когда резкий рост естественнонаучных данных, в частности
абсолютных датировок, заставил пересмотреть ряд устоявшихся представлений о хронологии и типологии
неолитической керамики и орнаментальных традиций. На региональном уровне произошел возврат к «клас- 
сической» трехчленной периодизации; наметилась тенденция к регионализации исследований для уточнения представлений о локальных вариантах и хронологической позиции материальных комплексов, специфике историко-культурных процессов. Делается вывод о необходимости формирования новой исследовательской парадигмы путем синтеза теорий среднего уровня с эмпирическими обобщениями.

Ключевые слова: Зауралье; неолит; историография; культурно-хронологическая концепция; периодизация; диффузионизм; эволюционизм; культурогенез; эмпирические обобщения; типология; керамические типы.

Основные вопросы, дискутируемые сегодня в археологической литературе по проблемам зауральского неолита, неразрывно связаны с классическими уже концепциями середины - второй половины XX века В.Н. Чернецова и О.Н. Бадера, а также Л.Я. Крижевской. Имена других, не менее заслуженных исследователей Уральского региона - А.Я. Брюсова, В.М. Раушенбах, Е.М. Берс, А.П. Окладникова, К.В. Сальникова, Г.Н. Матюшина, Н.П. Кипарисовой - были неоднократно упомянуты в специальных разделах обобщающих работ по неолиту $[1 ; 2]$, и, не преуменьшая их вклада в исследование зауральского неолита, данный обзор будет посвящен рассмотрению идей, ставших не только историографическим достоянием дисциплины, но и базой для развития современных концепций. Такой ретроспективный анализ предпринят с целью обозначить логику развития исследовательского поиска на протяжении второй половины XX - начала XXI века в контексте диалектического единства идей.

Первая культурно-хронологическая концепция зауральского неолита, прошедшая испытание временем и источниками, была предложена в середине XX века В.Н. Чернецовым. В.Н. Чернецов [3] выделил в развитии восточноуральской неолитической культуры три этапа, дав названия: козловский, юрьинскогорбуновский и чэстыйягский - для раннего, развитого и позднего этапов соответственно. Несколько позднее О.Н. Бадер предложил наименования «козловский», «полуденский» и «сосновоостровский» по опорным эпонимным памятникам тех же этапов неолита [4]. Историографически более устойчивой оказалась терминология О.Н. Бадера, хотя содержательная отсылка происходит к идее В.Н. Чернецова по хронологическому приоритету. Так было заложено представление о том, что хронологические этапы культурогенеза зауральского неолита заключаются в изживании прочерченно-накольчатых орнаментов и увеличении доли гребенчатых вплоть до полного доминирования.

Что касается культурологического содержании эпохи, формирование зауральского неолита, по В.Н. Чернецову, происходило под непосредственным влиянием кельтеминарской культуры, а по О.Н. Бадеру - на местной мезолитической основе, хотя и с заимствованием некоторых элементов материальной культуры с юга.

Л.Я. Крижевская не предложила культурно-периодизационной схемы, но создала социокультурную концепцию для зауральского неолита, подробно рассмотренную Л.Л. Косинской [5, с. 63-64]. Так, принимая позицию автохтонного сложения зауральского неолита, Л.Я. Крижевская отмечала сильное влияние казахстанских степей для Южного Зауралья и опосредованное - для Среднего [6, с. 113-115]. На этом основании она предложила деление неолитической культуры Зауралья на две общности - среднеуральскую и южноуральско-казахстанскую, обосо- бив в рамках последней казахстанские варианты, южноуральскую и западносибирскую лесостепную культурные общности [6, с. 115]. Основанием для выделения таких локальных групп были не только особенности материальных комплексов, но и отражение в них различных форм родственных объединений и отношений [6, с. 117]. То есть на фоне «генерализующих» идей зауральского неолита с широкой культурной общностью была сделана попытка предложить не столь однолинейный путь исследований, выделяя на основе пространственно-географического анализа вкупе со спецификой конкретных материальных комплексов более дробные культурные объединения [7, с. 161].

Итак, до конца 1980-х гг. в зауральском неолитоведении бытовало представление о единой восточноуральской неолитической культуре с тремя этапами развития, сложившейся при большем или меньшем воздействии кельтеминарской культуры.

В таком виде культурогенетические представления о зауральском неолите пребывали до 90-х гг. ХХ века. Накопление в 1980-е гг. принципиально новых данных позволило В.Т. Ковалевой предложить иную, двухлинейную и двухстадийную схему развития зауральского неолита, в которой симметрично выстроились местная и пришлая линии развития с ранним и поздним этапами (козловско-полуденская и кошкинско-боборыкинская линии). Термин «восточноуральская культура» был выведен из оборота; козловские и кошкинские древности были обозначены как «типы» или «группы», а статус самостоятельных культур получили полуденские и боборыкинские материалы $[1$, с. 5,15$]$. Тезис о кельтеминарском влиянии на сложение козловских древностей наследовал В.Н. Чернецов; третья стадия неолита по ЧернецовуБадеру в редуцированном виде упоминалась в качестве финального неолита в рамках полуденской культуры позднего неолита. Несмотря на активные миграционные процессы, для культур аборигенов и мигрантов постулируется параллелизм в сосуществовании. Простота и симметричность схемы позволили на том этапе упорядочить разнородные материалы, эффективно решая исследовательские задачи.

В дальнейшем развитии концепции В.Т. Ковалевой в соавторстве с С.Ю. Зыряновой козловские материалы также получают статус «культуры» [8, c. 38]; подчеркиваются этническая детерминированность материалов и дискретность развития кошкинской и боборыкинской культур. Допускается, впрочем, наличие ограниченных контактов между носителями кошкинской и боборыкинской традиций [9, c. 286]. Культурный диффузионизм предлагается для козловской линии развития, сложившейся на основе миграции кельтеминарского населения и трансформировавшейся в полуденские комплексы при инфильтрации носителей прикамских гребенчатых традиций $[10$, с. 63]. Таким образом, механизм культурогенеза, предложенный в рамках двухстадийной 
концепции, за четверть века перешел от умеренного диффузионизма к достаточно радикальному, связанному уже не просто с распространением и заимствованием отдельных культурных образцов, а с прямыми инвазиями носителей материальных культур.

Принципиально иным образом выглядела концепция, почти одновременно выдвинутая В.А. Захом. Начиная с 1987 г. он развивает гипотезу о формировании неолитических культур Зауралья на базе пришлой боборыкинской и автохтонной полуденской (в первоначальной версии), или сосновоостровской (в дальнейшем развитии идеи). В окончательном виде его схема была закреплена в 2006 г., а опубликована в развитом монографическом виде в 2009 г. [11], где постулировался ранненеолитический возраст боборыкинской и сосновоостровской культур, при взаимодействии которых сложились кошкинский и козловский керамические типы, а окончательной формой гетерогенного развития стала полуденская культура, ставшая результатом поглощения аборигенами культурных традиций мигрантов.

То есть принципиальное расхождение этих схем даже не столько в хронологическом «переворачивании» кошкинско-боборыкинских или боборыкинскокошкинских древностей, сколько в том, что схема В.Т. Ковалевой предполагает значительный параллелизм и изоляционизм разнокультурных групп населения, а концепция В.А. Заха утверждает однолинейное развитие неолитических традиций путем адаптации культуры мигрантов к аборигенной среде, с последующим видоизменением обеих. С точки зрения культурогенеза эта позиция занимает промежуточную нишу между диффуционизмом и эволюционизмом.

В рамках двухстадийной периодизации В.С. Мосиным предложен иной принцип культурогенеза, снимающий с древнего населения Зауралья изоляционизм. Он отмечает, что внутри экзогамных социумов происходило постоянное смешение носителей традиций, лишая материальные комплексы (керамические по преимуществу) типологической чистоты и однородности [12; 13]. Орнаментальные традиции, сложившись в раннем неолите на основе подражания природным орнаментирам, передавались в рамках брачно-семейных отношений и трансформировались с течением времени. Таким образом, керамический тип рассматривается в рамках традиций не столько как этнокультурный показатель, сколько как социокультурный маркер рода.

Сильной стороной данной идеи является снятие противоречия между взаимоисключающими позициями Ковалевой-Заха и соответствие материалам смешанных комплексов, к которым, судя по картографии памятников и полным публикациям некоторых из них (Евстюниха I, Полуденка I, Мергень 7), относится значительная часть памятников неолита. Кроме того, освобождение понятия «керамический тип» от жесткой этнокультурной детерминанты оставляет пространство для дискуссий о типологии и уточнения характеристик типов, что сегодня является назревшей методической задачей $[14$, с. $44 ; 15$, с. 23-24; 10, с. 63]. Данная культурогенетическая концепция может быть отнесена к эволюционизму, так как все трансформации материальных культур населения Зауралья основаны прежде всего на внутреннем импульсе.

Таким образом, в последнем десятилетии XX века и в первом десятилетии века XXI произошел отход от «классической» трехчленной периодизации неолита и усложнение схем культурогенеза. На базе двухчленной периодизации созданы три концепции, две из которых отмечают крайние точки диффузионизма (В.Т. Ковалева) и эволюционизма (В.С. Мосин), а третья занимает промежуточное положение (В.А. Зах). Внутреннее содержание культурных процессов в концепциях В.Т. Ковалевой и В.А. Заха связано с этнокультурными представлениями, а в работах В.С. Мосина - с социокультурными.

В начале XXI века, спустя четверть века после создания двухстадийной концепции, на протяжении которых она успешно отвечала на «вызовы истории» со стороны новых источников, археологами была накоплена, дополнена и обобщена большая база данных по абсолютным датам [16], что заставило сначала поставить вопрос о хронологическом приоритете отдельных орнаментальных традиций, а вскоре признать и некий кризис в зауральском неолитоведении и начать поиск путей решения.

Так, оказалось, что «архаичные» комплексы типа Евстюнихи I с преимущественно прочерченной техникой орнаментации имеют в рамках раннего неолита более поздние даты, а «финальные» гребенчатые комплексы позднего неолита почти синхронны полуденским. Несовпадение абсолютных дат со сложившейся схемой заставило уточнить характеристику евстюнихского типа керамики [8, с. 39]; однако, при некотором несовпадении данного описания с характеристиками опубликованного эпонимного комплекса, это привело к размытию представлений как о евстюнихском типе керамики, так и о козловской культуре и ее внутренней типологии и хронологии.

На материалах севера Западной Сибири, отличающихся большим разнообразием и своеобразием, произошел возврат к трехчленной периодизации неолита. Л.Л. Косинская предложила деление на ранний неолит 1, ранний неолит 2 и поздний неолит [17, c. 34] для локальной группы северных памятников; однако экстраполяцию этой схемы на материалы смежной территории Среднего Зауралья исследователь сочла не противоречащей имеющимся данным. В целом, историографически эта идея повторяет логику типологической хронологии с ранним козловским этапом и более поздним евстюнихским [8, c. 38-39], но базируется на всем имеющемся материале раннего неолита, а не одной козловской традиции.

Так как отказ от трехчленной периодизации В.Н. Чернецова был сделан на основании только типологии материала и логики его систематизации в рамках двухлинейного развития, сегодня обоснование двух- или трехчленной периодизационной шкалы - вопрос корреляции керамических типов и абсолютных дат с генезисом материальных комплексов региона. Резкий количественный рост дат качественно изменил хронологическую колонку неолита, существенно удревнив его [16]. Не менее значительно изменилось культурное наполнение эпохи: хронологический приоритет накольчатой орнаментальной традиции перед прочерченной, а также фактическая 
синхронность полуденских и гребенчатых материальных комплексов не только меняют вектор развития орнаментальных традиций, но и допускают не столь односложное направление эволюции материальных культур неолита Зауралья.

Так, ранненеолитические керамические тенденции Зауралья скорее демонстрируют большую близость комплексов при двухкомпомнентности, представляя собой кошкинскую и кокшаровско-юрьинскую посуду; некоторые экземпляры сходны до неразличимости, что уже было отмечено ранее [18, c. 22]. На смежной территории лесостепного Зауралья пока не составлена надежная культурнохронологическая колонка для ранненеолитических комплексов, а материалы многих памятников лесостепи еще не опубликованы, поэтому предлагать решение проблем культурогенеза на этом материале не представляется возможным. Непосредственно среднезауральские материалы скорее выглядят как «распадание» близкой, почти гомогенной накольчатой традиции на все более различающиеся по морфологическим и композиционно-орнаментальным признакам. Различные комплексы идут по пути дивергенции признаков и их рекомбинации, создавая с течением времени (в раннем неолите-2?) «классические» козловские образцы с их декоративным разнообразием на значительной территории.

Также сегодня выглядит несколько упрощенным и не совсем точным представление о том, что развитие козловско-полуденских керамических комплексов шло однолинейно от прочерченной орнаментации по пути включения все большего объема накольчатой, а затем гребенчатой компоненты. Материалы отдельных памятников - Кедровый мыс-1 (пока недатированный), а также датированный поздним неолитом комплекс Мергень 7 [15, с. 24] позволяют допустить сосуществование накольчатой «козловской» традиции совместно с полуденской и гребенчатой вплоть до трансформации комплексов в энеолитические [18, с. 23]. Также можно считать, что неолитические материалы стоянок Евстюниха I и Полуденка I представляют собой смешанные комплексы, оставленные носителями обеих орнаментальных традиций $[19$, с. $139 ; 14$, с. 71$]$. Таким образом, видится скорее некоторое смещение «акцента» в орнаментальной традиции с прочерчено-накольчатой на гребенчатую и развитие обеих традиций в рамках единого (в социальном смысле) социума, но не замещение одного варианта другим.

Еще одно следствие разрастания источниковой базы - тенденция к регионализации. Невозможность прямых экстраполяций культурно-хронологических схем неолита Среднего Зауралья на смежные территории стала очевидной первоначально для севера Западной Сибири. Так, Л.Л. Косинская пишет о том, что «под давлением» все новых данных, «уралоцентризм» в осмыслении источников оказывается все менее действенным методом. И напротив, выделение новых типов керамики укрепляет «представление о многообразии локальных проявлений неолитической культуры в рамках некой общности» [5, с. 65], что было предложено концепцией Л.Я. Крижевской.

Однако «экспансия» зауральских культур далеко на восток (имеются в виду приишимские и барабинские памятники озера Мергень и Автодром-2/2) ста- вит перед исследователями не только вопросы локальной хронологии (исследователи мергенских памятников придерживаются боборыкинско-кошкинской культурно-хронологической схемы), но и региональной типологии комплексов. Выявление отдельных артефактов, связанных с маханджарским импульсом - на памятниках Ук 6, Усть-Суерка-4, Кочегарово-1, Мергень-7, - вероятно, при дальнейших углубленных исследованиях сделает картину культурогенеза неолита Зауралья и Западной Сибири еще более сложной.

Итак, можно отметить, что значительный количественный прирост источниковой базы на протяжении последнего полувека (как материального корпуса, так и абсолютных дат) привел к качественным изменениям исследовательского поля. Во-первых, удревнение и усложнение культурно-хронологической колонки зауральского региона актуализирует вопросы внутреннего содержания периодизации неолита в контексте социальных и культурных процессов в соответствии с динамикой развития материальных комплексов. Во-вторых, и сам генезис материальных культур Зауралья и Западной Сибири требует значительного переосмысления на основе сопоставления абсолютных дат, выделенных/выделяемых культурных типов и локальных групп памятников. То есть необходимо соединение теорий среднего уровня (в терминологии Р. Мертона) с эмпирическими обобщениями для выработки непротиворечивой парадигмы. Два этапа развития культурно-хронологических концепций зауральского неолита со второй половины XX по начало XXI в. являются эпистемологической базой для синтеза нового научного знания.

\section{СПИСОК ЛИТЕРАТУРЫ:}

1. Мосин В.С., Григорьев С.А. Древняя история Южного Зауралья. Т. 1. Каменный век. Эпоха бронзы. Серия «Этногенез уральских народов». Челябинск: Изд-во ЮУрГУ, 2000. 532 с.

2. Ковалева В.Т. Неолит Среднего Зауралья: учебное пособие по спецкурсу. Свердловск. Издательство УрГУ, 1989. 82 с.

3. Чернецов В.Н. К вопросу о сложении уральского неолита // История, археология и этнография Средней Азии. М.: Наука, 1968. С. 41-53.

4. Бадер О.Н. Уральский неолит // Каменный век на территории СССР. М.: Наука, 1970. С. 157-171.

5. Косинская Л.Л. Л.Я. Крижевская и уральский неолит // Уральский исторический вестник. 2016. № 4 (53). С. 62-67.

6. Крижевская Л.Я. Неолит Южного Урала // МИА. 1968. № 141. 184 c.

7. Крижевская Л.Я. Некоторые данные о неолите и ранней бронзе западносибирского лесостепья // Сибирь и ее соседи в древности. Новосибирск, 1970. C. $153-162$.

8. Ковалева В.Т., Зырянова С.Ю. Продолжение дискуссии о зауральском неолите // Вопросы археологии Урала: сб. научных трудов. Екатеринбург; Сургут: Магеллан, 2008. Вып. 25. С. 30-43.

9. Ковалева В.Т., Зырянова С.Ю. Неолит Среднего Зауралья: Боборыкинская культура. Екатеринбург: Центр «Учебная книга», 2010. 308 с.

10. Зырянова С.Ю., Ковалева В.Т. Основные тенденции в изучении неолита Среднего Зауралья 
(XXI век) // Археологическое наследие Урала: от первых открытий к фундаментальному научному знанию (XX Уральское археологическое совещание): мат-лы всерос. (с междунар. участием) науч. конф. Ижевск. 2016. С. 61-64.

11. Зах В.А. Хроностратиграфия неолита и раннего металла лесного Тоболо-Ишимья. Новосибирск: Наука, 2009. 320 c.

12. Мосин В.С. Этнокультурные процессы на Урале в начале голоцена // Вестник ЮУрГУ (Серия «Социально-гуманитарные науки»). 2010. № 28 (204). Вып. 15. С. 44-49.

13. Мосин В.С. Экосоциальная атаптация населения центра Северной Евразии в конце плейстоцена начале голоцена (опыт археологического моделирования) // Уральский исторический вестник. 2010. Вып. 2 (27). С. 4-12.

14. Герасименко А.А. Характеристика керамики поселения Евстюниха I // Вопросы археологии Ура- ла: сб. научных трудов. Екатеринбург; Сургут: Магеллан, 2008. Вып. 25. С. 44-72.

15. Еньшин Д.Н. Керамический комплекс поселения Мергень 7 (Нижнее Приишимье): характеристика и интерпретация // Вестник археологии, антропологии и этнографии. 2015. № 2 (29). С. 15-27.

16. Выборнов А.А., Мосин В.С., Епимахов А.В. Хронология уральского неолита // Археология, этнография и антропология Евразии. 2014. № 1 (57). С. $33-48$.

17. Косинская Л.Л. Ранняя гребенчатая керамика в неолите Зауралья // Уральский исторический вестник. 2014. № 2 (43). С. 30-40.

18. Мосин В.С. Социокультурное пространство в позднем каменном веке // Вестник Пермского университета. Серия: История. 2016. № 1(32). С. 19-27.

19. Бунькова (Герасименко) А.А. Керамика из жилища 1 поселения Полуденка 1 // Вопросы археологии Урала: сб. научных трудов. Екатеринбург; Сургут: Магеллан. Вып. 26. 2011. С. 125-140.

\title{
«BACK TO THE FUTURE»: THE MAIN HISTORIOGRAPHICAL THEMES AND TOPICAL PROBLEMS OF THE NEOLITHIC OF THE URALS
}

(C) 2017

\author{
Yakovleva Ekaterina Sergeevna, researcher \\ Archaeological Research Center (Chelyabinsk, Russian Federation)
}

\begin{abstract}
The following paper deals with some problems of Trans-Urals Neolithic which are associated with the formation and development of basic cultural and chronological concepts. Three stages in conceptual historiography are identified. The first one refers to the mid-second half of the 20th century and is associated with the formation of the first cultogenesis schemes of the late Trans-Urals Stone Age by V.N. Chernetsov, O.N. Bader and L.Ya. Krizhevskaya. At the second stage at the end of the 19th - beginning of the 21st century their ideas were revised by V.T. Kovaleva in the framework of a two-stage and two-line concept. At the same time the hypothesis of V.A. Zakh was developed. Later V.S. Mosin proposed a socio-cultural scheme for the formation of an integrated society in the Neolithic Trans-Urals. The third - the modern stage - began approximately in the second decade of the 21st century when natural scientific data growth forced to reconsider a number of established ideas about the chronology and typology of Neolithic ceramics and ornamental traditions. At the regional level there was a return to the «classical» three-term periodization; there was a trend towards regionalization of research to clarify the notions of local variants and the chronological position of material complexes, specifics of historical and cultural processes. It is concluded that it is necessary to form a new research paradigm by synthesizing middle-level theories with empirical generalizations.

Keywords: Trans-Urals; Neolithic; historiography; cultural-chronological concept; periodization; diffusionism; evolutionism; culturogenesis; empirical generalizations; research paradigm; typology; ceramic types; ornamental tradition; absolute dates.
\end{abstract}

\section{ТЕХНОЛОГИЧЕСКИЕ ОСОБЕННОСТИ НАБОРА КЕРАМИКИ ВТОРОЙ ЧЕТВЕРТИ І ТЫС. Н.Э. ПОСЕЛЕНИЯ СОСЕНКИ УЛЬЯНОВСКОЙ ОБЛАСТИ} (C) 2017

Никитина Анна Валерьевна, аспирант кафедры социологии, политологии и истории Отечества Самарский государственный технический университет (г. Самара, Российская Федерация)

Аннотащия. В статье представлена типологическая и технологическая характеристика глиняной посуды поселения Сосенки Старомайнского района Ульяновской области. Среди имеющегося материала было выделено три морфологические группы сосудов на основании внешних признаков - формы профиля и способа обработки поверхности. Дальнейший технико-технологический анализ керамики, основанный на методике А.А. Бобринского, проводился на предмет определения характеристик исходного пластичного сырья, традиций составления формовочных масс и характера обжига сосудов. Анализ подготовительной стадии гончарного процесса подтвердил наличие некоторых различий и на уровне технологии в выделенных группах. Они в основном связаны с особенностями размерности и калибровки шамота в формовочных массах. В заключение предлагается предварительно связать данный комплекс с верхнедонским культурным традициям. Однако указывается, что весьма ограниченный объем материалов пока предполагает лишь необходимость его введения в научный оборот, не делая упор на культурные интерпретации. Датировка поселения на основании массового материала не может быть определена уже, чем в пределах фаз C2-D2. Поселение относится к до- 